\section{$\underset{\substack{\text { hommes } \\ \text { \& migrations }}}{ }$}

Hommes \& migrations

Revue française de référence sur les dynamiques

migratoires

$1300 \mid 2012$

Nouveaux modèles migratoires en Méditerranée

\title{
Khaled Osman, Le Caire à corps perdu
}

Vents d'ailleurs, 2011, 255 pages,18 euros

\section{Mustapha Harzoune}

\section{(2) OpenEdition}

\section{Journals}

\section{Édition électronique}

URL : http://journals.openedition.org/hommesmigrations/962

DOI : 10.4000/hommesmigrations.962

ISSN : 2262-3353

\section{Éditeur}

Musée national de l'histoire de l'immigration

\section{Édition imprimée}

Date de publication : 1 novembre 2012

Pagination : 166-167

ISSN : 1142-852X

\section{Référence électronique}

Mustapha Harzoune, « Khaled Osman, Le Caire à corps perdu», Hommes \& migrations [En ligne], 1300 | 2012, mis en ligne le 29 mai 2013, consulté le 22 septembre 2020. URL : http://

journals.openedition.org/hommesmigrations/962 ; DOI : https://doi.org/10.4000/hommesmigrations. 962

Ce document a été généré automatiquement le 22 septembre 2020.

Tous droits réservés 


\title{
Khaled Osman, Le Caire à corps perdu
}

\author{
Vents d'ailleurs, 2011, 255 pages,18 euros
}

\author{
Mustapha Harzoune
}

\section{RÉFÉRENCE}

Khaled Osman, Le Caire à corps perdu, Vents d'ailleurs, 2011, 255 pages,18 euros

1 Khaled Osman est un traducteur prolixe (Naguib Mahfouz, Gamel Ghitany, la Palestinienne Sahar Khalifa ou la Saoudienne Raja Alem) et talentueux puisque son travail fut primé, notamment en 1988 et en 2005. Avec Le Caire à corps perdu,il livre un premier et riche roman dont les ressorts de l'intrigue sont en partie liés à son activité professionnelle. La langue, sensuelle et suave, donne à entendre les bruits et les mots de la capitale égyptienne, portés par un populo bariolé, joyeux, farceur, empathique et gaillard.

2 Un Égyptien rentre au pays après des années d'exil mais, dans le taxi qui le cueille à la sortie de l'aéroport, notre homme est victime d'un malaise. Sayyed, le chauffeur, le laisse inanimé devant une pension, oubliant dans la précipitation sa veste sur la banquette arrière et sa valise dans le coffre. L'homme se réveille amnésique, ne sachant plus rien de son passé ni de lui-même. Seuls des extraits de romans ou de poèmes affleurent à sa conscience. Son identité se nourrit de ces pages lues et de son présent, au sein d'une pension où la patronne, Sett Baheyya, et les locataires (Faouzi l'éternel étudiant en médecine, Ibrahim le gardien, Khadra la femme de ménage et cuisinière, 'Azza l'étudiante en économie politique...) font assaut de prévenance, de solidarité et d'amitié pour réconforter et aider celui qu'ils surnomment "Nassi” à retrouver le chemin de son identité perdue.

3 Cajolé, choyé, Nassi vit de ces marques d'amitié et de ses réminiscences littéraires au point de se dire qu'il n'a peut-être besoin de rien d'autre. Serait-ce une façon de prendre quelque distance avec l'impératif mémoriel, la dictature des sédiments et le fardeau des fausses fidélités qui finissent par écraser les vivants? "Malgré toute son horreur, cette amnésie provisoire avait tout de même du bon: elle lui permettait de renouer 
directement avec son enfance en passant outre les idées noires, les angoisses et les appréhensions qui encombraient ordinairement son esprit." cuisine (le petit déjeuner à la pension, un plat de fèves, le jus de la canne à sucre dans la rue ou la qamareddine...). Pour remonter le fil de la mémoire et du passé, Khaled Osman construit un habile procédé littéraire où les pérégrinations mémorielles de son personnages se doublent d'une enquête menée par les services de police. Car le capitaine Mounir (et sa zélée Nesrine) veille et surveille ces expatriés qui reviennent au pays pour y semer le désordre, bousculer les ordonnancements politiques, les constructions nationalistes et identitaires. L'émigré-immigré est partout un empêcheur de vivre en rond...

6 Accompagné de Faouzi, Nassi déambule dans la ville qui elle aussi a perdu ses repères : “Alors il n'y a pas que moi qui perd la mémoire, le pays tout entier est en train d'oublier son passé!" Celui, lointain, des origines - "à écouter certains, on pourrait croire que notre civilisation n'a véritablement émergé qu'au VIIe siècle" - ou celui, plus proche, riche d'une diversité culturelle et humaine, aujourd'hui disparue.

Il se tourne vers Raouf Effendi, un vieil archiviste qui, au fond d'un petit café discret où l'on peut siroter un cognac, lui propose trois identités possibles, dont celle d'un indic des services! Nassi, tel un Driss Chraïbi, s'emporte : "Un être humain ne se réduit pas à son parcours (...). Ce qui ne ment pas, en revanche, ce sont les convictions, les valeurs, les principaux traits de caractère! C'est pourquoi je te le dis et le répète : ce type n'est pas moi."

8 Nassi pressent qu'il pourrait bien venir de France. Il s'en va interroger les services du consul. Mais voilà, la France, patrie des droits de l'homme et du raffinement, goûte davantage l'antique et les vieilles pierres, un peu moins le pays et son peuple. Là où d'autres candidats à l'exil subissent quotidiennement files d'attente, vexations administratives, condescendance et plus récemment procès en criminalisation, lui essuie simplement une suspicion polie et une fin de non-recevoir. Renvoyé à une nonréalité, un bannissement, une absence d'identité, "les vieux démons resurgissent : sa part d'ombre qu'il a toujours portée comme un fardeau. (...). Cette impression de n'appartenir à aucune collectivité, de n'être chez lui nulle part, d'avoir le mal du pays où qu'il se trouve. Au fond, il n'a jamais su trouver sa place, et ce qui lui arrive en ce moment ne fait qu'entériner tragiquement un état de fait préexistant."

9 Le Caire et ses habitants sont l'autre personnage de ce roman. Khaled Osman montre l'humour, le goût pour la dérision, la solidarité, l'entraide, la légèreté et la joie de vivre de la rue cairote malgré la pauvreté et les frustrations. Ainsi, demander son chemin à un Égyptien comporte quelques risques : le natif du cru brille moins par la rigueur que par l'impérieuse préoccupation de rendre service, quitte à vous éloigner de votre destination. Le souci de l'autre importe plus ici que l'exactitude topographique. Ces marques d'attention et ces bonnes intentions ne valent-elles pas mille fois mieux que l'indifférence qui court les rues des capitales occidentales? D'ailleurs, Nassi se dit fatigué de l'Europe, de son individualisme et des plaintes des nantis. Il avait besoin "de revenir à la simplicité" (un plat de fèves partagé avec une galette de pain baladi), "à l'imprévoyance et au fatalisme". Peut-être que l'auteur force ici un peu le trait sur les qualités respectives et les défauts spécifiques des deux sociétés. À moins qu'il ne s'agisse de montrer, par un effet de contraste, les dérives d'une modernité à la sauce occidentale qui imprègne aussi les identités des sociétés arabes, et ici Le Caire et ses 
habitants : multiplication des projets immobiliers, individualisme croissant, perte des valeurs et des repères... Pour autant, les amoureux continuent de flirter sur les rives du Nil ou sur les hauteurs du Muqattam où, malgré le moralisme ambiant, ils se retrouvent pour "se déclarer leur flamme" et croire "encore à la vie...".

10 À la pension, Nassi reste un homme sans nom. L'amnésie, comme la littérature, est aussi un refuge, une façon de fuir le réel, sa dictature et ses contraintes. Pour retrouver son identité, peut-être devra-t-il, lui aussi, croire de nouveau "à la vie". 